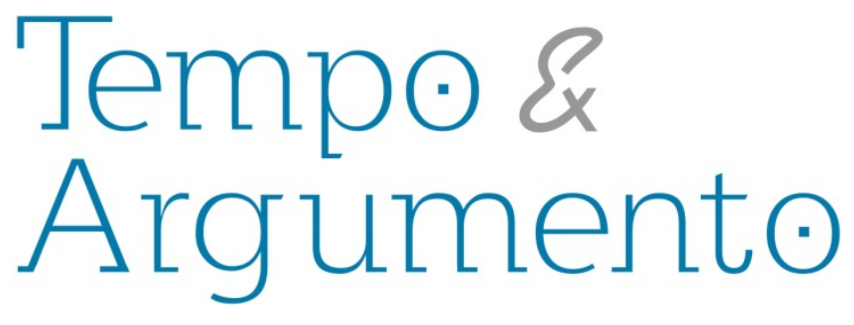

\title{
Esporte galístico: transformações urbanas e discursos de galistas acerca das brigas de galos (1980-2014)
}

\begin{abstract}
Resumo
Este artigo busca fazer um levantamento historiográfico sobre a prática das brigas de galos, observando como esta atividade se constitui e se altera frequentemente em decorrência de fatores como a urbanização, sensibilidades e civilização. Dessa forma, dialogando com pesquisas sobre a história do esporte, das cidades e sensibilidades, o texto aborda inicialmente as brigas de galos como prática histórica, como foi e como ainda é representada. Em seguida, observa-se como ela foi representada no momento em que os esportes se consolidam. Para finalizar, destacase a região da Grande Florianópolis, trazendo depoimentos que possibilitam pensar as brigas de galos através de seus participantes, de que maneira eles a entendem e que discursos utilizam frente a dicotomias como rural-urbano e esporte-lazer.
\end{abstract}

Palavras-chave: Brigas de galos; Urbanização; Esportes.

\section{Para citar este artigo:}

CORRÊA, Misael Costa. Esporte galístico: transformações urbanas e discursos de galistas acerca das brigas de galos (1980-2014). Revista Tempo e Argumento, Florianópolis, v. 8, n. 17, p. 384 - 402. jan./abr. 2016.

DOI: $10.5965 / 2175180308172016384$

http://dx.doi.org/10.5965/2175180308172016384 


\title{
Gamecock Sport: urban transformations and cockfighters discourses about cockfighting (1980-2014)
}

\begin{abstract}
This article aims to make a historiographical research regarding the cockfights practice, perceiving the ways its constitution changes often according to factors as urbanization, sensibilities transformations and concepts of civilization. Thereby, first this article approaches cockfighting as a historical practice, exploring researches on sports, cities and sensibilities history. The goal is to reflect about cockfights representations in the past and in the present, with focus on the moment of sports emergence. Finally, the article highlights Florianópolis region, discussing testimonials that allow to observe cockfighting through the eyes of cockfighters and audience. These testimonials bring information about participants views regarding understanding of cockfighting related to discourses based on dichotomies such as rural-urban and sport-leisure.
\end{abstract}

Keywords: Cockfighting; Urbanization; Sports.

\section{As brigas de galos no campo esportivo}

Os esportes têm uma ligação íntima com o processo de urbanização. Foi a partir do processo de urbanização que muitas práticas e atividades corporais passaram a ser denominadas de "Sports" - que segundo os historiadores Melo e Fortes (2010, p. 12) a palavra era "originária do francês antigo 'disport", e foi registrada pela primeira vez na Grã-Bretanha do século XV, mas é somente na transição dos séculos XVIII e XIX que ela assume o sentido atual. Esta associação entre urbanização e esporte advém das novas formas de compreensão do uso que, outrora, se chamava passatempo, das alterações sociais e, principalmente, das relações de trabalho que fundaram novas dinâmicas em 
Dentro dessa nova dinâmica, entendida como esporte, foram incluídas diversas práticas realizadas com animais, como corridas de cavalos, touradas e lutas de galos, cães e ursos. Exemplo disso são dois livros publicados na Inglaterra, nos séculos XIX e XX: British Sports, de Henry Alken, publicado em 1821, e Old English Sports, de autoria de Frederick Hackwood, publicado em 1907. Ambos descrevem práticas esportivas consideradas antigas no Reino Unido, entre algumas delas vale citar a caça e a luta entre animais: como cães, cães contra ursos, a matança de ratos e as brigas de galos. Em um contexto semelhante, Norbert Elias comenta:

As pessoas da Grã-Bretanha pré-industrial desfrutavam todas as espécies de passatempos - luta de galos, combates de touros e combates de ursos, queima de gatos vivos em cestos, boxe profissional, assistência a execuções públicas - que parecem "não civilizados" nos termos dos valores atuais. (ELIAS, 1992 p. 335)

As brigas de galos, interesse principal deste texto, antes de qualquer menção à ideia de esporte, segundo as mais diversas fontes históricas, teria surgido na Ásia, com a domesticação dos galináceos, sobretudo na China e Índia, e difundida no Oriente Próximo pelos Persas. ${ }^{1}$ Desta região, os galos combatentes foram paulatinamente introduzidos na Europa por fenícios, gregos e romanos, cabendo a estes últimos a disseminação por todo seu Império e até mesmo além de suas fronteiras (SCOTT, 2009, p. 152). Na Bretanha, consta que César, quando partiu para a sua conquista, lá encontrou criações de galos de briga, que há muito tempo já constituíam um velho passatempo entre os habitantes, conforme escreve George Rilley Scott (2009, p. 104):

\footnotetext{
${ }^{1}$ Cockfighting spread from Asia after the Persian armies conquered India in the 4 th century B.C. The Persians adopted the sport and are thought to be at least partly responsible for its introduction to the Mediterranean basin through military and commercial pursuits. The sea-faring Phoenicians are also thought to be responsible for the widespread distribution of gamefowl from the orient to Africa, the Middle East, and along the European coast. ULLAH, Disponível em: <http://www.aseellovers.20m.com> Acesso em: 22 dez. 2011.
} 
Muitos escritores são da opinião que os romanos introduziram o esporte na Grã-Bretanha. Outros afirmam com igual confiança que já era existente na época da conquista romana, apontando para a declaração de Júlio César no sentido de que os antigos bretões criavam aves por prazer e diversão ao invés de alimentos. De qualquer forma, é provável que os romanos foram os responsáveis pela introdução de esporas artificiais e a primeira forma de brigas de galo organizadas. ${ }^{2}$

Neste trecho, é importante notar sua classificação como esporte, mesmo que isto possa ser considerado um tanto anacrônico. De qualquer maneira, as brigas de galos possuem sistemas distintos por onde existiram, permitindo salientar que, historiograficamente, elas foram representadas simbolicamente como o enaltecimento da masculinidade, da virilidade e da bravura. Keith Thomas (1998, p. 219), historiador inglês, afirma que

Tal como a caça fora valorizada por simular a atividade bélica, as brigas de galo e o açulamento de ursos foram apreciados enquanto representação de combate privado. O galo era um símbolo de coragem masculina e façanhas sexuais (duplo sentido muito importante). Ele lutava até a morte, ainda que cegado ou gravemente ferido; era louvado por sua "coragem invencível" e sua "resolução", e o próprio esporte era elogiado como uma diversão nobre e heroica.

Outro exemplo disso é o que escreve Clifford Geertz (1989, p. 283-284), entre os balineses:

Para quem quer que tenha permanecido algum tempo em Bali, a profunda identificação psicológica dos homens balineses com seus galos é incontestável. (...) O fato é que eles são símbolos masculinos par excellence é indubitável e tão evidente para os balineses como o fato de que a água desce pela montanha.

Na América, os galos chegaram quase que concomitantemente à conquista. Assim, podemos apontar os portugueses e espanhóis como introdutores dos galos no Novo Mundo. A prática difundiu-se amplamente e esteve muito disseminada no Brasil. Pode-se supor que, sem intenção de ser, a briga de galos foi um dos "esportes" mais difundidos

\footnotetext{
${ }^{2}$ Tradução livre para: Many writers are of opinion that the Romans introduced the sport into Britain. Others assert with equal confidence that it was already existent at the time of the Roman Conquest, pointing out the statement of Julius Caesar to the effect that the ancient Britons bred fowls for pleasure and diversion rather than food. At any rate it is probable that the Romans were responsible for the introduction of artificial spurs and the first form of organised cockfighting.
} 
Muitas das sensibilidades, principalmente sobre a proteção dos animais, vêm se transformando há vários séculos. Segundo Keith Thomas (1998), foi a partir do crescimento das cidades e o distanciamento do modo de vida rural que se formaram novas percepções e concepções do homem moderno inglês para com os animais:

O novo sentimento começou a ser expresso por citadinos bem situados, afastados do processo agrícola e propensos a considerar os animais como bichos de estimação, não como uma criação para o trabalho, quer por clérigos rurais educados, cujas sensibilidades eram diferentes das dos homens rústicos em cujo meio viviam. No século XVII, notava-se que a caça custava demasiado tempo e dinheiro para ser adequada a homens de negócio; e os movimentos reformistas para a abolição dos esportes cruéis estavam firmemente baseados na cidade. (THOMAS, 1998, p. 190191)

Claro que são sociedades distintas. A Inglaterra dos séculos XVII e XVIII trouxe diversas experiências urbanas que, em muitos casos, afastaram muitas pessoas de outras experiências, algumas delas tidas como rurais. No Brasil, o processo de urbanização é muito posterior e as experiências são diferentes, mas em algum momento se deparam com situações análogas às já enfrentadas em outros lugares do mundo, sobretudo, aquelas que são tomados como paradigmas para a formação de sua urbanidade e civilidade.

No Brasil, durante muito tempo, a formação de uma civilidade esteve concentrada na cidade do Rio de Janeiro, que era o centro radiador e dali servia de referência para outros lugares do país. Dessa maneira, é ali que vão circular e ecoar os primeiros discursos visando legitimar certas práticas, dentre as quais, as práticas esportivas. Ao mesmo tempo, formam-se discursos de aversão e repulsa a determinadas práticas, das quais destacaremos alguns esportes que utilizam animais.

De acordo com Victor Andrade Melo (2008, p. 9-36), touradas e cavalhadas foram, desde o Brasil Colonial até início do século XX, uma importante manifestação, largamente 
praticada em datas comemorativas. Para a realização dessas atividades eram montadas arenas, as quais podiam ser apreciadas publicamente. A diminuição de sua incidência no Brasil deve-se, em parte, ao projeto civilizatório que proibiu tais práticas. Melo (2008) aprofunda essa questão analisando os rodeios como uma prática que substituiu gradativamente as touradas, o que lhe permite afirmar que "trata-se de um formato mais próximo do campo esportivo de uma prática outrora perseguida e proibida" (MELO, 2008, p. 20).

Sobre a categorização dos esportes no Brasil, este mesmo historiador afirma que:

Entre essas atividades, algumas já existiam no país antes mesmo da chegada da prática esportiva, e seu não desenvolvimento certamente tem relação com um quadro contextual de grande importância para a própria construção da ideia de nação brasileira. A partir de determinado momento consideradas "bárbaras" e ultrapassadas, foram perseguidas e proibidas; contudo, seguiram existindo por um bom tempo, dividindo espaço com outras atividades "civilizadas", como passou a ser considerado esporte notadamente a partir da década final do século XIX. (MELO, 2009, p. 37)

As brigas de galos, segundo o autor, são apontadas como muito populares: "no Rio de Janeiro do século XIX, era tão grande a presença e a popularidade das brigas de galo que Machado de Assis as chamava de 'Jockey Club dos pobres”' (MELO, 2008, p. 20). O escritor Machado de Assis, ao caracterizá-las dessa maneira, buscava ironizá-las o que demonstra muito bem o imaginário social e político dos intelectuais e classes dominantes do período. Sobre o mesmo período, ou mesmo anteriormente, Keith Thomas demonstra que na Inglaterra também havia esta repugnância das classes sociais mais abastadas, alguns letrados e religiosos, que passaram a se voltar contra certas diversões populares, indicando, assim, transformações na sensibilidade em virtude da ascensão da burguesia. Mesmo assim, afirma que tal fato não é exclusividade do século XIX. No século XVII já era possível observar algumas destas aversões às brigas de galos, como ressaltou acerca do governo protestante de Cromwell:

É verdade que os esportes animais aos protestantes repugnavam por serem associados ao ruído, ao jogo e a desordem; e foi com base nisso que as rinhas e o arremesso de paus contra galos foram proibidos por uma ordenação do Protetor em 1654. (THOMAS, 1998, p. 188) 
Assim, muitas dessas alterações visavam inculcar novas formas de ver, perceber e dar sentido ao mundo, o que foi muito bem percebido por Thomas em relação à Inglaterra:

[...] nos séculos XVII e XVIII muito das pressões para eliminar os esportes cruéis provinha de um anseio por disciplinar a nova classe trabalhadora segundo padrões mais elevados de ordem pública e hábitos mais industriosos. (...) $\mathrm{O}$ amor às criaturas brutas frequentemente se associava a repugnância pelos hábitos de ordem inferiores; e a opinião de classe média mostrava-se tão ofendida com a desordem que os esportes animais criavam quanto com a crueldade neles presente. Os maus tratos aos animais, pensava Willian Baker em 1770, eram "um vício ao qual o vulgo inculto muito se dedica". Trata-se, também na opinião de Willian Jones de Nayland, em 1771, "de um dos vícios característicos das pessoas mais baixas e vis". Durante todo o século XIX, pareceu óbvio que era "entre as classes inferiores da sociedade que grassavam os atos cruéis". Os vilões eram "os rudes e devassos" cocheiros, "os patifes velhacos e insensíveis do mercado de Smithfield" e os execráveis barqueiros. A lei de 1835 , contra a crueldade infligida aos animais, proclamava a intenção de reduzir tanto os sofrimentos das criaturas mudas quanto "a desmoralização do povo". ( THOMAS, 1998, p. 221-222)

A partir desses fragmentos, começa-se a compreender alguns dos motivos que levaram a proibição das rinhas de galos e também de várias outras práticas socioculturais. Discursos fundados em uma moral puritana e burguesa, associados às novas sensibilidades, produzidos a partir do desenvolvimento capitalista e urbano, e que estão a todo o momento se entrecruzando e criando mecanismos de intervenção do Estado nas populações e nos indivíduos. Isso quer dizer que as sensibilidades, como estão dadas, não são algo natural ao ser humano. As relações com o seu meio estão em constantes modificações e isso pode ser localizado dentro de uma perspectiva histórica, tentando entender em que momentos e circunstâncias essas modificações são mais perceptíveis.

\section{Resistência às rinhas}

$\mathrm{Na}$ atualidade, as brigas de galos, além de já contarem com toda a carga negativa imposta pelos discursos civilizatórios, também e, principalmente, são apontadas como maltrato aos animais, crueldade. No Brasil, é frequentemente enquadrada como crime 
Rio de Janeiro, Santa Catarina, Rio Grande do Norte, Salvador, etc.) que visavam permitir as brigas de galos.

Apesar de ser uma polêmica ainda em aberto, é importante o exercício de pensá-la como resistente, pois são mencionadas como populares há muito tempo e ainda persistem em alguns meios. Exemplo disso é o Rio de Janeiro - onde existiram touradas e dificilmente a encontraríamos atualmente - no entanto, as brigas de galos ainda são possíveis de se encontrar. Pelo menos foram encontradas em 2004 e noticiadas no Brasil inteiro, pois um famoso publicitário foi encontrado no chamado "Clube Privê Cinco Estrelas", um importante rinhadeiro localizado em Jacarepaguá. Além disso, o fato de a Assembleia do Rio de Janeiro aprovar em 2005 uma lei permitindo as rinhas é um indício da existência de uma atividade "subterrânea" e uma rede de sociabilidades capaz de dialogar exitosamente com os poderes institucionalizados.

Entretanto, a briga de galos se localiza num vazio quanto à sua classificação como esporte, lazer, prática cultural, "barbárie” ou “crueldade”. Geralmente, os praticantes se referem como um esporte, mesmo não sendo um consenso entre os mesmos. Em uma discussão sobre a mobilização dos galistas, com o objetivo de legalizar a prática, um indivíduo em um grupo de e-mails, restrito a criadores, escreveu:

creio que o momento atual não é o da "legalização do esporte", até porque, convenhamos, a briga de galos não é um esporte... é um lazer, um passatempo, um entretenimento, uma atividade popular e cultural. Foge, totalmente, às definições de esportes reconhecidas pelos Estados (países), inclusive pelo COI. (ANÔNIMO, 16 de maio de 2013)

Ainda assim, é possível considerar esporte, pelo menos pelas considerações apontadas por Melo (2008, p. 10):

Sem considerar os aspectos legais e morais, se dialogarmos com a ideia de Pierre Bourdieu sobre a constituição de um campo (1983), podemos afirmar que estamos nos referindo a uma prática esportiva. Existem treinadores e métodos de treinamento para os "atletas", forma como 
alguns criadores chamam seus animais; isto é, há um corpo profissional especializado. As regras são rígidas e devem ser seguidas por todos que frequentam os espaços institucionalizados. Percebe-se um mercado de consumo gestado ao redor das rinhas, que envolve não só as apostas e os produtos adequados para potencializar a performance dos "competidores" (aparelhos para a boa preparação, alimentação adequada, implementos para as esporas, entre outros), como também a negociação dos animais, algo que movimenta grandes quantias. Há um calendário próprio de competições e a existência de Federações em muitos Estados demonstra que a briga de galo se trata de uma prática com relativa organicidade no nosso país, mesmo que fira a legislação em vigor.

E de certa maneira, as briga de galos foram entendidas como um esporte, e bem difundido durante uma época. Autores de diversas áreas do conhecimento, que se debruçaram sobre o tema, tais como Francisco Elias, Renato Santos Silva, Victor Dominguez y Perles, Marie Cegarra, o próprio Keith Thomas, entre muitos outros, se utilizam do termo esporte para designar a prática.

Certamente não é um esporte no qual o atleta é o homem, mas adentrando-se ao campo do simbólico e analisando, conforme Geertz (1989) propôs acerca dos balineses, o condicionamento dos animais, sua postura no manejo e na luta, bem como o resultado do embate, podem ser representações das corporificações de desejos humanos, ou como observou Silva (2011, p. 99) em sua dissertação em Ciências Sociais:

A rinha de galos é vista como um esporte que proporciona lazer e funciona como uma espécie de confronto simulado [...] com a delegação de lutar feita aos galos é regulamentada para proporcionar prazer aos espectadores, através de momentos de tensão e excitação. Como consequência, dessa delegação de luta do homem para o galo, o primeiro passa a ter um papel secundário, de mero espectador, já que o papel principal, ou em outras palavras, a estrela do espetáculo passa a ser o galo, que tem a incumbência de representar o seu dono no combate.

De fato, quando realizei minhas pesquisas sobre as brigas de galos, chamava-me bastante a atenção, apesar de não me ser estranho, o fato dos depoentes denominarem a briga de galos como um esporte, "o esporte galístico"3. Principalmente quando os

\footnotetext{
${ }^{3}$ Presente nos depoimentos de PEREIRA, ZIMMERMAN, SANTOS, SOUZA, LOPES e RODRIGUES. Ressalto aqui que todos os nomes de depoentes são fictícios.
} 
ilegalidade, pois mesmo a noção de esporte fica um pouco comprometida, por conta de vários discursos que a ilegitimam e, principalmente, por não ser uma atividade profissionalizada. Poucas pessoas vivem disso que denominam esporte. Todos os depoimentos apontam o fato de que ninguém vive de apostas. O galista Antonio Zimmerman, de Florianópolis, conta que "o galo de briga não dá lucro para ninguém, quem cria é um apaixonado pelos galos combatentes e, evidentemente, que minha renda vem da minha aposentadoria e de honorários advocatícios" (ZIMMERMAN, 2011). Por seu turno, o galista Bartolomeu Gonçalves, de Florianópolis, diz: “o verdadeiro galista e preservador só investe na criação sem objetivo de lucro, pois, isto é paixão pelos animais." (GONÇALVES, 2011). Já o galista Pedro Dias, também da Capital, é mais sucinto: “Ninguém consegue viver de apostas! Não dá lucro!” (DIAS, 2011). Assim como Pereira (2011): “Não, isso aqui é um esporte. Na realidade não dá lucro, é um prazer que a gente tem! Se der pra tirar os gastos, pra gente já tá bom."

Lopes (2011), ao ser perguntado se é possível viver das apostas, declarou:

Não, isso aí é uma ilusão. Nunca ouvi dizer que alguém ficou rico por causa de galo de briga. Isso é simplesmente esporte. Ou o cara que se dedica só pra isso, pra criar e vender, se ele for apostador não adianta, ele vai perder. Eu nunca ouvi dizer que alguém ficou rico com galo, a não ser que ele crie e venda, que é outro departamento. Mas apostar não. É claro que tem uns mais espertos [nas apostas] que conseguem ganhar mais, mas isso é paixão... eu não conheço ninguém que tenha ficado rico com isso! Porque hoje se ganha, amanhã perde, aposta no galo dele e ganha, aí aposta no galo de outro e já perde. Mas a maioria tem a sua profissão, suas coisas.

As rinhas não são um esporte institucionalizado, se assim pode-se definir, porém, suas regras são muito semelhantes em todo o Brasil. Usa-se o mesmo tipo de espora e bicos e as rinhas tem a mesma duração: 55 minutos divididos, geralmente, em "banhos" ou "refrescos"4 de 20, 20 e 15 minutos. A espora artificial largamente usada é conhecida

\footnotetext{
${ }^{4}$ Banhos ou refrescos são como os galistas denominam os períodos da luta. Em esportes como, por
} 
durante as rinhas.

\section{As brigas de galos em Florianópolis: discursos sobre si acerca do esporte num ambiente em transformação}

Tentou-se até aqui demonstrar as brigas de galos como um esporte, prática e diversões das mais comuns no Brasil, ou da maneira como Paulo Adriano Jatobá (2006), em sua monografia de especialização em História, referencia o autor e galista Francisco Elias:

Para Elias, a luta de galos no Brasil é, por assim dizer, um esporte do interior e da cidade. $E$ mais do que isso, é uma das mais autênticas tradições do nosso povo, em que participam todas as camadas sociais, inclusive citados em diversos trabalhos literários de reconhecido valor. $\mathrm{O}$ esporte galístico é considerado por Elias como um dos mais democráticos, compartilhando nele gente de todas as camadas sociais, o pobre, o rico, o operário e o intelectual. (ELIAS, 1992, p. 9)

Esta afirmação pretende enfatizar o caráter esportivo da atividade com vistas a fortalecer sua legitimidade, porém esconde uma série de problemas. O primeiro deles é a questão de gênero: exclusivamente masculino. O outro é que as classes não são tão harmônicas como estão apresentadas. Certamente as apostas mais volumosas não se dão entre ricos e pobres, mas entre ricos e ricos. Por estes motivos existem rinhas para as mais diversas classes e preferências, que os galistas frequentam conforme suas possibilidades financeiras, com algumas mobilidades entre os grupos, o que é um fator de identificações em seu interior.

Antes de prosseguir essa narrativa, é preciso deixar claro, pelo menos, duas dimensões da atividade das brigas de galos pesquisada na região de Florianópolis, muito embora não se trate de uma peculiaridade. A primeira delas é a briga de galos como uma 
rinhas. Naquela época, em que não eram tão comuns as galinhas poedeiras ${ }^{5}$, nem as rações de postura ${ }^{6}$, era importante ter um galo no quintal, pois existia e ainda existe, a crendice de que um galo incentiva as galinhas a porem ovos. Ainda assim, o galo era necessário como maneira de fertilizar ovos, e, consequentemente, manter a produção dos animais e criá-los, tanto para o abate de consumo próprio, como para produção de ovos.

Nestas condições, desenvolveram-se tipos de rinhas que estiveram muito difundidas em áreas semiurbanas e semirrurais, como é o caso, no passado, de muitos distritos e atuais bairros de Florianópolis e cidades próximas, onde a briga de galos parecia ser uma diversão acessível, que podia acontecer num domingo ou feriado, quando os homens se encontravam nas vendas para prosear, tomar aguardente e jogar. Dentre os jogos poderiam ser encontrados, por exemplo, o baralho, o dominó, bocha e também brigas de galos. Esta última parece ter decaído, assim como outras práticas que caracterizavam estes espaços e que, o urbano, de certa maneira modificou, tanto pelas relações sociais como pelas estruturas físicas que passam a ordenar novas experiências.

A segunda dimensão da briga de galos é aquela em que os praticantes se denominam como galistas e denominam a atividade como um esporte: aí fazem parte pessoas que se dedicam exclusivamente à criação destes animais, com a finalidade de fazer as rinhas. Este grupo é composto por um número menor de participantes, mas, geralmente, com maior capacidade de locomoção dentro de determinado espaço. Enquanto aqueles, que faziam brigas de galos como diversão, - e que geralmente eram e ainda são, depreciados pelos “desportistas”, através de adjetivos pejorativos como, por exemplo, “preá”, ou apontados como quem não entende de galos de briga, que não

\footnotetext{
${ }^{5}$ As denominadas poedeiras são galinhas geneticamente modificadas para maior produção de ovos. Podem ser de duas raças, as Legorne (Brancas) e as Rodes ou Isa Brow (Vermelhas). São criadas geralmente em granjas a base de rações que estimulam essa maior produção, podendo produzir em média de 280 a 300 ovos por ano. (N.E.)

${ }^{6}$ Rações especiais, geralmente com o acréscimo de calcário, estimulando as fêmeas a produzirem maior quantidade de ovos. (N.E.)
} 
uns galos e fazer pequenas apostas. Este tipo de briga pode-se dizer que foi endêmica e sua diminuição pode ser descrita como um epifenômeno do processo de urbanização.

Contudo, voltando às identidades, vale ressaltar a maneira como Jatobá (2006, p. 11) descreve as divisões entre os praticantes:

Os criadores de galos estão divididos em dois grupos: o galista e o preá. Os galistas, criadores conceituados, normalmente de condições financeiras privilegiadas. Eles se destacam numericamente nas vitórias por possuírem uma criação de galo mais eficaz. E o "preá", termo pejorativo utilizado para identificar os criadores que não dispõem de uma estrutura adequada para um bom preparo de suas aves, bem como os recursos necessários para se obter um reconhecimento de seus adversários. A expressão "preá" denota, falta de conhecimento do indivíduo.

"Preá" é praticamente o antônimo de galista. Para quem briga galos, e trata isso como um esporte, é um grave insulto ser chamado de "preá”, pois, no imaginário dos galistas, essa denominação seria exatamente àquele sujeito que não leva o galo para uma competição com regras claras e estabelecidas: aves de mesmo peso, altura, sem a escolha de adversário, desprovido de puas (esporas), entre outras coisas. Seria o sujeito que carrega um galo embaixo do braço, esperando para fazer uma disputa em um lugar qualquer ("na porta do bar, embaixo de uma laranjeira, de uma bananeira, num cafezeiro, num chão batido", como disse Rodrigues).

Mas a noção de "preá" pode ir além disso, até porque alguém seria "preá" numa determinada situação e em outra não, como, por exemplo, os que frequentam os rinhadeiros da região mas não participam dos torneios quando vêm de longe, os chamados galistas fortes. Logo, eles podem ser considerados os "preás", em relação a estes galistas “fortes", pois nos torneios as apostas eram altas e a "parada" incompatível com o seu poder aquisitivo. 
Neste sentido, a pesquisa sobre as brigas de galos em Florianópolis apontou pelo menos estes dois tipos de rinhas. Parece ter havido um tipo de rinha, bastante comum há mais de trinta anos e que era feita sem muita estrutura, a qual o depoente Manoel Cardoso denominou como uma "brincadeira". Nesse meio havia pessoas que praticavam não só as brigas de galos, mas também a farra do boi (prática comum na região), contudo, não é o que apontam os galistas. No grupo de galistas, as declarações são no sentido de que não há qualquer proximidade entre as duas atividades, além do que, nenhum dos galistas identifica a rinha de galos como uma brincadeira, mas como um esporte.

Estes esportistas destinam suas horas livres à criação desses animais ou, se possível, contratam tratadores, investem na criação de dezenas de frangos sem garantias de qualquer lucro em apostas. Pelo menos em Santa Catarina, desde 2005, estão sem amparo legal, sofrendo com perseguições e acusações, porém, mesmo assim mantêm, na medida do possível, a atividade. O urbano, assim, torna-se um problema quando literalmente causa um incômodo maior nas outras pessoas. Pessoas vivem na cidade, às vezes convivendo com ruídos de construções, veículos, empresas, odores de lixo ou esgoto, mas não querem, sem fazer qualquer tipo de acusação, escutar um galo cantando às seis horas da manhã, nem sentir cheiro de esterco. Isto é absolutamente compreensível, no entanto, servem aqui como maneira de estranhar a sociedade urbana, para a qual, talvez, uma das possíveis explicações se refere aos desejos e ao que se espera quando se vive no ambiente urbano.

Ainda assim, interessa-me o quanto essa dimensão profissionalizada, como modalidade que procurou driblar muitos inconvenientes, nem todos é claro, se manteve em determinados grupos ou locais onde são menos vulneráveis. Neste ponto, encontramse importantes respostas e questionamentos quando se trata de práticas, das cidades e do urbano, como elas recortam umas as outras.

Por isso, foi importante para a pesquisa conversar com estas pessoas, e posso dizer que fui bastante surpreendido quando perguntei a vários depoentes se o crescimento da cidade implicava na continuidade das brigas de galos. Uma fala para exemplificar é a de Francisco Lopes (2011): 
Não. O crescimento da cidade não influi em nada, porque quando um centro é maior, mais galistas tem. E melhores! Rinha de galo não significa dizer que é de interior, rinha de galo é um esporte de qualquer nível social e de cidades. Geralmente cidade grande é a que tem os melhores galistas. Os grandes centros, Rio de Janeiro, São Paulo, Curitiba, Porto Alegre, capitais... O Palácio do Galo que tinha lá em Recife, eram todos na capital. Não é interior, no interior tem a chance de criar melhor, tem mais espaço, criam em lugares abertos, cria em maior quantidade, pode ser isso. Mas geralmente, os galistas de maior tradição estão na cidade.

Através destas palavras podemos pensar a briga de galos não como uma atividade puramente rural, ou como herança de um passado rural. Claro que a criação desses animais requer espaços um pouco maiores do que aqueles oferecidos pelos grandes centros urbanos, contudo, mesmo as grandes cidades possuem suas "ilhas de ruralidade", seus espaços "rururbanos", como os bairros rurais. Além do que, muitos dos galistas vivem nas cidades, mas possuem suas criações em sítios e áreas mais afastadas e, geralmente, contratam terceiros para criarem e tratarem seus animais.

Nos centros urbanos, o fator principal das queixas contra a atividade se dá muito mais em função da falta de condições sanitárias e pelos ruídos produzidos pelas aves, do que propriamente pelo fato a que elas se destinam. Muito antes das pessoas saberem que se trata de aves combatentes, incomodam-se com os odores e ruídos e denunciam às vigilâncias sanitárias.

O fator rinha é um problema quando descoberto e/ou denunciado, por isso, nos últimos anos existe a preferência por locais mais afastados das áreas mais conturbadas, o que muitas vezes não garante a proteção contra investidas policiais.

Este é um fator que tem afastado muitos galistas das rinhas, entretanto, mesmo com maior temor das investidas policiais, muitos deles não se dispuseram a encerrar suas criações, ainda que tenham se dedicado menos a elas, como Lopes (2011), quando lhe perguntei se continuou a criar galos, após encerrar seu próprio rinhadeiro: “Menos! A gente parou, mas mantém como hobby, meia dúzia de galos, umas galinhas. Não tinha mais aquela qualidade e motivos para investir muito. Porque é um esporte que sempre tem que se estar investindo." 
Estes indícios vêm demonstrando como certas práticas, mesmo sendo condenadas e perseguidas, persistem e, muitas vezes, se invisibilizam mesmo numa sociedade marcada pelo controle. Por outro lado, temos muitas pessoas, no caso os adeptos das rinhas de galos, utilizando-se de discursos datados na história com vistas a legitimar suas práticas. Pelo menos assim, podemos entender as rinhas de galos quando são nomeadas como esporte, ou como muitos galistas procuram se afirmar agora: como preservadores da espécie.

Longe de deslegitimarmos estas autodenominações, procuramos na medida do possível, compreender o galismo como atividade social permeada de discursos, conflitos sociais, políticos e legais e que, de uma maneira ou outra, continua a existir e criar, numa acepção certeauniana, táticas, tanto em ambientes urbanos como rurais.

\section{Referências}

AMARAL, Afonso: Afonso Amaral: depoimento oral [6 de Nov. de 2011]. Entrevistador: Misael Costa Corrêa. Palhoça/SC. Arquivo WAV, acervo do entrevistador.

ANÔNIMO. [mensagem pessoal] Mensagem de correio eletrônico recebida por: <grupo de galistas>. em: 16 mar. 2013.

AULER, Marcelo. Duda Mendonça já pagou fiança de mil reais e é solto. Revista Consultor Jurídico. _Sexta-feira, 22 de outubro de 2004. ", de ). Disponível em:

<www.conjur.com.br/2004-out-22/duda_mendonca_pagou_fianca_mil_reais_solto> Acesso em: 5 de jun. de 2011. 21:15:00

CARDOSO, Manoel. Manoel Cardoso: depoimento oral [05 de jul. de 2011] Entrevistador: Misael Costa Corrêa. Florianópolis/SC. Arquivo WAV, acervo do entrevistador.

CEGARRA, Marie. Le Cercle, le plume, le sang: etude anthropologique des combats de coqs dans le Nord de la France. 1987. 279 f. Dissertação (Mestrado) - Université de Lille II, Lille, 1987.

CHARTIER, Roger. A história cultural entre práticas e representações. Rio de Janeiro: Bertrand Brasil; Lisboa [Portugal]: Difel, 1990. 244 p. 
CORREA, Misael Costa. Costume proibido: a rinha de galos na Grande Florianópolis (19802011). 2012. 149 p. Dissertação (mestrado) - Universidade do Estado de Santa Catarina, Centro de Ciências Humanas e da Educação, Curso de História, Florianópolis, 2012.

DIAS, Pedro. Pedro Dias: depoimento oral e escrito [08 de set. de 2011] Entrevistador: Misael Costa Corrêa. Florianópolis/SC. Arquivo WAV, acervo do entrevistador.

DOMINGUES, Valdir: Valdir Domingues: depoimento oral [6 de Nov. de 2011]. Entrevistador: Misael Costa Corrêa. Palhoça/SC. Arquivo WAV, acervo do entrevistador.

DOMÍNGUES I PERLES, Víctor L. Sport gallístico a la riña de gallos: transformaciones de una práctica cultural en el proceso de civilización. Revista de Antropología Experimental, Jaén (Espanha), n. 1, p.429-440, jun. 2001.

DUNES, Alan. The Cockfighting: A Casebook. Madison, Wisconsin, EUA: Wisconsin, 1994. $302 \mathrm{p}$.

ELIAS, Francisco. Galos de briga e brigas de galos. 2 ed. Rio de Janeiro: [sem editora], 1978.

ELIAS, Norbert. A busca da excitação. Lisboa: DIFEL, 1992. 421p.

FOUCAULT, Michel. A ordem do discurso: aula inaugural no College de France, pronunciada em 2 de dezembro de 1970. 18 ed. São Paulo: Loyola, 2009. 79 p.

GEERTZ, Clifford. A interpretação das culturas. 1 ed. Rio de Janeiro: LTC, 1989.

GONÇALVES, Bartolomeu. Bartolomeu Gonçalves: depoimento oral e escrito [27 de ago. de 2011] Entrevistador: Misael Costa Corrêa. Florianópolis/SC. Arquivo WAV, acervo do entrevistador.

HOBSBAWM, E. J.; RANGER, T. O. A invenção das tradições. 3 ed. São Paulo: Paz e Terra, 2002. $316 \mathrm{p}$.

JATOBÁ, Paulo Adriano. A cultura da briga de galos: O galeão de Jacobina nos anos de 1960 a 1970. 2006. 41 p. Monografia de Especialização - Universidade do Estado da Bahia, Departamento de Ciências Humanas, Curso de Pós-Graduação em História, Cultura Urbana e Memória, Jacobina - Bahia, 2006.

LEFEBVRE, Henri. De lo rural a lo urbano. 3 ed. Barcelona: Península, 1975. 
LEI que regula briga de galo é inconstitucional. Revista Consultor Jurídico. Sexta-feira, 27 de maio de 2011. ") Disponível em: http://www.conjur.com.br/2011-mai-27/lei-estado-rioregula-briga-galo-inconstitucional. Acesso em: 14 de jul. de 2011. 19:00:00

LOPES, Francisco: Francisco Lopes: depoimento oral [4 de nov. de 2011]. Entrevistador: Misael Costa Corrêa. São José/SC. Arquivo WAV, acervo do entrevistador.

MARINHO, Fabrício Cabral dos Anjos. Galismo: cultura popular e esporte ou crime ambiental? 2009. Monografia (graduação) - Centro Universitário de Ensino Superior do Amazonas, Curso de Direito, Manaus, 2009.

MELO, Victor Andrade de. O que é "Sport"?: tensões na definição do campo esportivo na cidade do Rio de Janeiro do Século XIX. IHGB, Rio de Janeiro, v. 169, n. 439, p.9-36, 2008.

MELO, Victor Andrade de.; FORTES, Rafael. História do Esporte: panorama e perspectivas. Fronteiras, Dourados, Ms, v. 12, n. 22, p.11-35, dez. 2010.

MELO, Victor Andrade de. Das touradas às corridas de cavalo e regatas: primeiros momentos da configuração do campo esportivo no Brasil. In: DEL PRIORE, Mary; MELO, Victor Andrade de. História do esporte no Brasil: do Império aos dias atuais. São Paulo: UNESP, 2009. 566p.

NORA, Pierre. Entre memória e história: a problemática dos lugares. Projeto História, São Paulo, n. 10, dez. p. 7-28, 1993.

PEREIRA, Vicente. Vicente Pereira: depoimento oral [29 de jul. de 2011] Entrevistador: Misael Costa Corrêa. São José/SC. Arquivo WAV, acervo do entrevistador.

RODRIGUES, Sandro: Sandro Rodrigues: depoimento oral [4 de Nov. de 2011]. Entrevistador: Misael Costa Corrêa. Palhoça/SC. Arquivo WAV, acervo do entrevistador.

SANTOS, Débora. Supremo derruba lei do RJ que permitia rinha de galo. G1., Globo. com. Rio de Janeiro, Quinta-feira, 26 de maio de 2011.", de . Disponível em:

http://g1.globo.com/rio-de-janeiro/noticia/2011/05/supremo-derruba-lei-do-rj-que-permitiarinhas-de-galo.html. Acesso em: 31 de mai. de 2011. 22:10:00

SANTOS, Patrício: Patrício Santos: depoimento escrito [11 de set. de 2011]. Entrevistador: Misael Costa Corrêa. Florianópolis-Araranguá/SC. Email, acervo do entrevistador.

SCOTT, George Ryley. The history of cockfight. 50 ed. Midhurst - West Sussex: Beech Publishing House, 2009. 221 p. 
SILVA, Renato de Carvalho Santos. De homens e galos: um estudo antropológico sobre "um jogo absorvente" na região central do Rio Grande do Sul. 2011. 137 f. Dissertação (Mestrado) - Curso de Ciências Sociais, Departamento de Ciências Sociais e Humanas, UFSM, Santa Maria, RS, 2011.

SOUZA, Dário: Dário Souza: depoimento oral [4 de nov. de 2011]. Entrevistador: Misael Costa Corrêa. São José/SC. Arquivo WAV, acervo do entrevistador.

THOMAS, Keith. $O$ Homem e o mundo natural: mudanças de atitude em relação às plantas e aos animais, 1500-1800. São Paulo: Companhia das Letras, 1998.

ULLAH, Nadem. History of Aseel. Gujrat, Paquistão. [sem data] Disponível em: <http://www. aseellovers.20m.com> Acesso em: 22 jan. 2009, 23:12:55.

WACKWOOD, Frederick W. Old English Sports. Uckfield, East Sussex (Inglaterra): Published by The Naval \& Military Press Ltd. 2007.361 p.

ZIMMERMAN, Antonio. Antonio Zimmerman: depoimento oral e escrito. [29 de ago. de 2011]. Entrevistador: Misael Costa Corrêa. Florianópolis/SC. Arquivo WAV, acervo do entrevistador.

Recebido em 30/09/2014 Aprovado em 08/04/2016

Universidade do Estado de Santa Catarina - UDESC Programa de Pós-Graduação em História - PPGH

Revista Tempo e Argumento Volume 08 - Número 17 - Ano 2016 tempoeargumento@gmail.com 